\title{
Article
}

\section{BARD1 Pathogenic Variants Are Associated with Triple-Negative Breast Cancer in a Spanish Hereditary Breast and Ovarian Cancer Cohort}

\author{
Paula Rofes ${ }^{1,2,3}{ }^{(D}$, Jesús Del Valle ${ }^{1,2,3}{ }^{\mathbb{D}}$, Sara Torres-Esquius ${ }^{4}$, Lídia Feliubadaló 1,2,3 ${ }^{(D)}$, Agostina Stradella ${ }^{1,2,5}$, \\ José Marcos Moreno-Cabrera 1,2,3 ${ }^{\mathbb{D}}$, Adriana López-Doriga ${ }^{6,7}$, Elisabet Munté 1,2,3 ${ }^{\mathbb{D}}$, Rafael De Cid ${ }^{8}$, \\ Olga Campos ${ }^{1,2}$, Raquel Cuesta ${ }^{1,2}$, Álex Teulé ${ }^{1,2}$, Èlia Grau ${ }^{2,9}$, Judit Sanz ${ }^{10}$, Gabriel Capellá ${ }^{1,2,3}$ (D), \\ Orland Díez ${ }^{11,12}$, Joan Brunet ${ }^{5,13,14}$ (D) Judith Balmaña ${ }^{4}$ and Conxi Lázaro ${ }^{1,2,3, *}$
}

1 Hereditary Cancer Program, Catalan Institute of Oncology, IDIBELL, 08908 L'Hospitalet de Llobregat, Spain; profes@iconcologia.net (P.R.); jdelvalle@iconcologia.net (J.D.V.); lfeliubadalo@iconcologia.net (L.F.); astradella@iconcologia.net (A.S.); jmoreno@igtp.cat (J.M.M.-C.); emunte@iconcologia.net (E.M.); ocampos@iconcologia.net (O.C.); rcuesta@iconcologia.net (R.C.); ateule@iconcologia.net (Á.T.); gcapella@iconcologia.net (G.C.)

2 Program in Molecular Mechanisms and Experimental Therapy in Oncology (Oncobell), IDIBELL, 08908 L'Hospitalet de Llobregat, Spain; eggarces@iconcologia.net

check for updates

Citation: Rofes, P.; Del Valle, J.; Torres-Esquius, S.; Feliubadaló, L.; Stradella, A.; Moreno-Cabrera, J.M.; López-Doriga, A.; Munté, E.; De Cid, R.; Campos, O.; et al. BARD1 Pathogenic Variants Are Associated with Triple-Negative Breast Cancer in a Spanish Hereditary Breast and Ovarian Cancer Cohort. Genes 2021, 12, 150. https://doi.org/10.3390/ genes 12020150

Academic Editors:

Irmgard Irminger-Finger and Magda Ratajska

Received: 18 December 2020

Accepted: 20 January 2021

Published: 23 January 2021

Publisher's Note: MDPI stays neutral with regard to jurisdictional claims in published maps and institutional affiliations.

Copyright: (c) 2021 by the authors. Licensee MDPI, Basel, Switzerland. This article is an open access article distributed under the terms and conditions of the Creative Commons Attribution (CC BY) license (https:/ / creativecommons.org/licenses/by/ $4.0 /)$.
3 Centro de Investigación Biomédica en Red de Cáncer (CIBERONC), 28929 Madrid, Spain

4 Hereditary Cancer Genetics Group, Vall d'Hebron Institute of Oncology (VHIO), Medical Oncology Department, University Hospital Vall d'Hebron, Universitat Autònoma de Barcelona, 08035 Barcelona, Spain; storres@vhio.net (S.T.-E.); jbalmana@vhio.net (J.B.)

5 Medical Oncology Department, Catalan Institute of Oncology, IDIBELL, 08908 L'Hospitalet de Llobregat, Spain; jbrunet@iconcologia.net

6 Oncology Data Analytics Program (ODAP), Catalan Institute of Oncology, 08908 L'Hospitalet de Llobregat, Spain; alguerra@iconcologia.net

7 Consortium for Biomedical Research in Epidemiology and Public Health (CIBERESP), 28029 Madrid, Spain

8 Genomes for Life-GCAT Lab Group, IGTP, Institut Germans Trias i Pujol (IGTP), 08916 Badalona, Spain; rdecid@igtp.cat

9 Hereditary Cancer Program, Catalan Institute of Oncology, IGTP, 08916 Badalona, Spain

10 Genetic Counselling Unit, Medical Oncology Department, Althaia Xarxa Assistencial Universitària de Manresa, 08243 Manresa, Spain; jsanz@althaia.cat

11 Catalan Health Institute, Vall d'Hebron Hospital Universitari, 08035 Barcelona, Spain; odiez@vhio.net

12 Hereditary Cancer Genetics Group, Vall d'Hebron Institute of Oncology (VHIO), 08035 Barcelona, Spain

13 Hereditary Cancer Program, Catalan Institute of Oncology, IDIBGI, 17007 Girona, Spain

14 Medical Sciences Department, School of Medicine, University of Girona, 17007 Girona, Spain

* Correspondence: clazaro@iconcologia.net; Tel.: +34-93-2607145

\begin{abstract}
Only a small fraction of hereditary breast and/or ovarian cancer (HBOC) cases are caused by germline variants in the high-penetrance breast cancer 1 and 2 genes (BRCA1 and BRCA2). BRCA1associated ring domain 1 (BARD1), nuclear partner of $B R C A 1$, has been suggested as a potential HBOC risk gene, although its prevalence and penetrance are variable according to populations and type of tumor. We aimed to investigate the prevalence of BARD1 truncating variants in a cohort of patients with clinical suspicion of HBOC. A comprehensive BARD1 screening by multigene panel analysis was performed in 4015 unrelated patients according to our regional guidelines for genetic testing in hereditary cancer. In addition, 51,202 Genome Aggregation Database (gnomAD) non-Finnish, non-cancer European individuals were used as a control population. In our patient cohort, we identified 19 patients with heterozygous $B A R D 1$ truncating variants $(0.47 \%)$, whereas the frequency observed in the gnomAD controls was $0.12 \%$. We found a statistically significant association of truncating $B A R D 1$ variants with overall risk (odds ratio $(\mathrm{OR})=3.78 ; \mathrm{CI}=2.10-6.48$; $\left.p=1.16 \times 10^{-5}\right)$. This association remained significant in the hereditary breast cancer $(\mathrm{HBC})$ group $\left(\mathrm{OR}=4.18 ; \mathrm{CI}=2.10-7.70 ; p=5.45 \times 10^{-5}\right)$. Furthermore, deleterious BARD1 variants were enriched among triple-negative $\mathrm{BC}$ patients $(\mathrm{OR}=5.40 ; \mathrm{CI}=1.77-18.15 ; p=0.001)$ compared to other $\mathrm{BC}$ subtypes. Our results support the role of $B A R D 1$ as a moderate penetrance $\mathrm{BC}$ predisposing gene and highlight a stronger association with triple-negative tumors.
\end{abstract}


Keywords: $B A R D 1$; breast cancer; triple-negative breast cancer; ovarian cancer; hereditary breast and ovarian cancer; moderate cancer risk

\section{Introduction}

Hereditary breast and ovarian cancer (HBOC) risk has been traditionally linked to germline pathogenic variants (PVs) in breast cancer 1 and 2 genes (BRCA1 and BRCA2). However, only $20-30 \%$ of high-risk families carry PVs in these genes [1]. Gradually, PVs in various other genes with different degrees of penetrance have also been associated with breast cancer (BC) and/or ovarian cancer (OC) risk [2]. Several genes that are either interacting with $B R C A 1 / 2$ or involved in DNA damage response pathways have also emerged as potential candidates that may account for some of the missing heritability of these so-called BRCAX families, although their associated risks have not been fully established [2].

BRCA1-associated ring domain 1 (BARD1) was first discovered in 1996 as the nuclear partner of BRCA1 and became one of the earliest candidates investigated [3]. It is localized on chromosome 2 at position 2q35 and encodes a protein of 777 amino acids that contains one N-terminal Really Interesting New Gene (RING)-finger domain, four Ankyrin (Ank) repeats and two C-terminal tandem BRCA1 C Terminus (BRCT) domains [4,5]. BARD1 shows structural homology with BRCA1 and they directly interact through their RING domains. The BARD1-BRCA1 obligate heterodimer functions as both an E3 ubiquitin ligase and as a direct mediator of homologous recombination for the recruitment of RAD51 to the sites of DNA double-strand break (DSB) $[3,6,7]$. Furthermore, BARD1 is also involved in other BRCA1-independent functions, including p53-mediated apoptosis [8].

To date, the role of BARD1 in cancer predisposition remains inconclusive. Several case-control studies have reported a higher prevalence of deleterious BARD1 variants among BC patients, supporting its role as a moderate risk predisposing gene [9-11]. An enrichment of BARD1 PVs among triple-negative breast cancer (TNBC) cases has also been evidenced [12-14]. Contrarily, some studies have been unable to detect a significant association of $B A R D 1$ with breast cancer risk $[15,16]$. Likewise, the association between $B A R D 1$ and overall OC risk has shown controversial results [17-19]. Taken together, there is still insufficient evidence to elucidate the role of BARD1 in breast and/or ovarian cancer predisposition. In the present study, we have investigated the prevalence of deleterious germline BARD1 variants in a cohort of 4015 patients with clinical suspicion of hereditary breast and/or ovarian cancer, with the aim of elucidating the role of BARD1 in cancer predisposition in the Spanish population.

\section{Materials and Methods}

\subsection{Patients and Controls}

A total of 4015 index patients with a personal or family history suggestive of hereditary $\mathrm{BC}$ and / or OC referring at genetic counseling units of the Catalan Institute of Oncology (ICO) and Vall d'Hebron (HVH) hospitals were included in the present study. Clinical characteristics for all enrolled patients were the following: patients with $\mathrm{BC}$ before 40 years; patients with TNBC before 60 years; male BC patients; patients with non-mucinous OC; patients with a family history of two cases of $B C$ before age 50; patients with three or more cases of first-degree BC; patients with a case of bilateral BC associated with another case of $\mathrm{BC}$ in the family. Informed written consent for both diagnostic and research purposes was obtained from all patients, and the study protocol was approved by the ethics committee of Bellvitge Biomedical Research Institute (IDIBELL; PR278/19) and Vall d'Hebron Hospital (PRAG102-2016). A set of 194 Spanish cancer-free individuals from the Genomes For Life-Cohort Study of the Genomes of Catalonia (GCAT) cohort [20] were screened with the same cancer panel as ICO patients. 


\subsection{NGS Panel Testing}

In the ICO cohort, genetic testing was performed on genomic DNA using the nextgeneration sequencing (NGS) custom panel I2HCP, which comprises 122-135 hereditary cancer (HC)-associated genes, depending on the version used [21]. Copy number analysis was performed from NGS data using DECoN [22] with parameter optimization [23]. Copy number variants (CNVs) in BARD1 were validated using custom multiplex ligationdependent probe amplification (MLPA) probes designed according to the instructions provided by MRC-Holland. Likewise, $26 \mathrm{HC}$-associated genes were included in the $\mathrm{HVH}$ NGS panel (BRCA Hereditary Cancer MASTR Plus kit, Agilent Technologies, Santa Clara, CA, USA). Copy number analysis was performed from NGS data using MASTR Reporter (Agilent Technologies, Santa Clara, CA, USA) and putative CNVs were validated by RTPCR analysis [24]. For this study, we considered any variant that originates a premature stop codon or affects canonical splice site positions $(+1,+2,-1,-2)$ as a pathogenic or likely pathogenic variant (pathogenic variant hereinafter); all of them were classified as (likely) pathogenic following the American College of Medical Genetics and Genomics and the Association for Molecular Pathology (ACMG/AMP) guidelines [25] and were confirmed by Sanger sequencing.

\subsection{Variant Nomenclature}

Human Genome Variation Society (HGVS)-approved guidelines [26] were used for BARD1 variant nomenclature using NM_000465.2 (LRG_297). For variant numbering, nucleotide 1 is the A of the ATG translation initiation codon.

\subsection{Co-Segregation Analysis and Loss of Heterozygosity ( $\mathrm{LOH})$}

Both analyses were performed by Sanger sequencing when samples from relatives or tumor DNA were available.

\section{5. gnomAD Analysis}

The Genome Aggregation Database (gnomAD) non-Finnish European population, non-cancer dataset (v2.1.1) [27] was used as a control population. Variants were downloaded and filtered to identify predicted loss-of-function variants in BARD1. CNV screening was performed in the gnomAD SVs v2.1 dataset.

\subsection{Statistical Analysis}

Differences in allele frequency between cases and controls were determined by the Fisher exact test. Odds ratios (OR) and the corresponding 95\% confidence intervals (CI) were determined for two-by-two comparisons. Statistical tests were carried out using $\mathrm{R}$ v.3.5.1.

\section{Results}

In our study cohort of 4015 unrelated patients with hereditary breast and/or ovarian cancer, 476 PVs were identified as per clinical gene panel analysis (Table 1), representing $11.86 \%$ patients harboring PVs in high- to moderate-penetrance BC/OC-associated genes. In addition, with the aim of investigating the role of PVs in the BARD1 gene, we performed an exhaustive analysis of truncating, splicing and CNVs in this gene. Nineteen patients carried heterozygous germline PVs in BARD1, resulting in a carrier frequency of $0.47 \%$. Among them, one patient additionally carried a PV in the HBOC-predisposing gene $B R C A 2$ (patient 10; BRCA2 c.3264dupT; p.(Gln1089Serfs*10)) (Table 2). The remaining 18 BARD1mutated index patients tested negative for PVs in other BC/OC genes (for more details of the genes analyzed according to the phenotype, refer to Feliubadaló et al., 2019 [24]). Thus, after excluding carriers of other HBOC PVs, the global BARD1 carrier frequency throughout our cohort of patients was $0.45 \%$. The percentage of deleterious BARD1 variants in the subset of patients with hereditary breast cancer (HBC) was $0.50 \%, 0.42 \%$ in hereditary ovarian cancer (HOC) cases and $0.33 \%$ in patients with HBOC (Table 1 ). No 
$B A R D 1$ PVs were identified in our set of 194 cancer-free individuals. In order to increase the control cohort, loss-of-function BARD1 variants were screened in the non-Finnish European gnomAD 2.1.1 (non-cancer) population, identifying a total of 61 heterozygous carriers out of 51,202 individuals $(0.12 \%)$. The comparison of carrier frequencies between the patient and control cohorts revealed an overall significant association of BARD1 PVs $\left(\mathrm{OR}=3.78 ; \mathrm{CI}=2.10-6.48 ; p=1.16 \times 10^{-5}\right)$. This association was also significant in the HBC group $\left(\mathrm{OR}=4.18 ; \mathrm{CI}=2.10-7.70 ; p=5.45 \times 10^{-5}\right)$. Moreover, deleterious BARD1 variants demonstrated an increased risk in the HOC and HBOC groups, although the differences did not reach statistical significance $(\mathrm{OR}=3.53, \mathrm{CI}=0.71-10.86, p=0.06$ and $\mathrm{OR}=2.77, \mathrm{CI}=0.33-10.47, p=0.17$, respectively) (Table 1 ).

The clinical phenotype of BARD1-mutated patients is depicted in Table 2. Sixteen developed BC at a median age of 41 years (27-63), younger than the general population (median age at diagnosis 62 years old in females, according to NCI's SEER 21 2013-2017 Program). Of these, 10 were diagnosed with at least one TNBC. We compared the prevalence of deleterious $B A R D 1$ variants between women diagnosed with TNBC and other BC subtypes and found significant differences according to the triple-negative status of carriers. deleterious BARD1 variants were enriched in HBC families where the index case developed TNBC (OR = 5.40; $\mathrm{CI}=1.77-18.15 ; p=0.001$ ) (Table 3 ). Regarding OC cases, three patients were diagnosed at a median age of 62 years (59-62) - two were diagnosed with high-grade ovarian serous carcinoma (HGOSC) and one with endometrioid carcinoma (EC). 
Table 1. Summary of the next-generation sequencing (NGS) panel results in our hereditary breast and/or ovarian cancer (HBOC) cohort and in the control populations.

\begin{tabular}{|c|c|c|c|c|c|}
\hline Clinical Indication & Number of Patients (\%) & Genes Tested by Phenotype & Number of PVs (\%) & BARD1 (\%) & $\begin{array}{c}\text { BARD1 Excluding Patients } \\
\text { with Other PVs (\%) }\end{array}$ \\
\hline $\begin{array}{l}\text { Only Hereditary Breast } \\
\text { Cancer, HBC }\end{array}$ & $2622(65.31 \%)$ & $\begin{array}{c}\text { ATM, BRCA1, BRCA2, CHEK2, } \\
M L H 1, M S H 2, M S H 6, \text { PALB2, TP53 }\end{array}$ & $\begin{array}{c}270 \text { PVs }(10.30 \%): \text { ATM (34), } \\
\text { BRCA1 (71), BRCA2 (90), } \\
\text { CHEK2 (27), MLH1 (3), MSH2 } \\
\text { (1), MSH6 (2), PALB2 (37), } \\
\text { TP53 (5) }\end{array}$ & $\begin{array}{c}13(0.50 \%) \\
\mathrm{OR}=4.18(2.10-7.70) * * \\
p=5.45 \times 10^{-5}\end{array}$ & $\begin{array}{c}13(0.50 \%) \\
\mathrm{OR}=4.18(2.10-7.70) * * \\
p=5.45 \times 10^{-5}\end{array}$ \\
\hline $\begin{array}{l}\text { Only Hereditary Ovarian } \\
\text { Cancer, HOC }\end{array}$ & $715(17.81 \%)$ & $\begin{array}{c}\text { BRCA1, BRCA2, BRIP1, MLH1, } \\
M S H 2, M S H 6, R A D 51 C, R A D 51 D\end{array}$ & $\begin{array}{l}93 \text { PVs (13.01\%): BRCA1 (39), } \\
\text { BRCA2 (35), BRIP1 (6), MLH1 } \\
\text { (1), MSH6 (4), RAD51C (4), } \\
\text { RAD51D (4) }\end{array}$ & $\begin{array}{c}3(0.42 \%) \\
\mathrm{OR}=3.53(0.71-10.86) \\
p=0.06\end{array}$ & $\begin{array}{c}3(0.42 \%) \\
\mathrm{OR}=3.53(0.71-10.86) \\
p=0.06\end{array}$ \\
\hline $\begin{array}{l}\text { Hereditary Breast and } \\
\text { Ovarian Cancer, HBOC }\end{array}$ & $608(15.14 \%)$ & $\begin{array}{c}\text { ATM, BRCA1, BRCA2, BRIP1, } \\
\text { CHEK2, MLH1, MSH2, MSH6, } \\
\text { PALB2, RAD51C, RAD51D, TP53 }\end{array}$ & $\begin{array}{c}104 \text { PVs (17.11\%): ATM (7), } \\
\text { BRCA1 (45), BRCA2 (32), } \\
\text { BRIP1 (7), CHEK2 (6), MSH2 } \\
\text { (1), PALB2 (3), RAD51C (1), } \\
\text { RAD51D (1), TP53 (1) }\end{array}$ & $\begin{array}{c}3(0.49 \%) \\
\mathrm{OR}=4.16(0.83-12.79) * \\
p=0.04\end{array}$ & $\begin{array}{c}2(0.33 \%) \\
\mathrm{OR}=2.77(0.33-10.47) \\
p=0.17\end{array}$ \\
\hline $\begin{array}{l}\mathrm{HBC} / \mathrm{HOC} / \mathrm{HBOC}+\text { Other } \\
\text { clinical indications }\end{array}$ & $70(1.74 \%)$ & Details in Ref: [24] & $\begin{array}{l}9 \text { PVs }(12.86 \%): A T M(2) \\
\text { BRCA1 (2), BRCA2 (1), MSH6 } \\
\text { (2), PTEN (1), RAD51C (1) }\end{array}$ & $0(0 \%)$ & $0(0 \%)$ \\
\hline \multirow[t]{4}{*}{ Total } & 4015 & & $476(11.86 \%)$ & $\begin{array}{c}\mathrm{OR}=3.99(2.25-6.77)^{* * *} \\
p=3.48 \times 10^{-6}\end{array}$ & $\begin{array}{c}\mathrm{OR}=3.78(2.10-6.48)^{* *} \\
p=1.16 \times 10^{-5}\end{array}$ \\
\hline & & & \multirow{3}{*}{\multicolumn{2}{|c|}{$\begin{array}{l}\text { Controls studied } \\
\text { Spanish population cohort }(n=194) \\
\text { gnomAD non-Finnish European, non-cancer cohort } \\
\qquad(n=51,202)\end{array}$}} & \\
\hline & & & & & $0(0 \%)$ \\
\hline & & & & & $61(0.12 \%)$ \\
\hline
\end{tabular}

Table 2. Genotype and phenotype data of index patients carrying heterozygous germline pathogenic variants in the BRCA1-associated ring domain 1 (BARD1) gene.

\begin{tabular}{|c|c|c|c|c|c|c|c|}
\hline Family & Clinical Indication & Cancer Type (Age at dx) & Tumor Phenotype & Family History (Age at dx) & BARD1 PV (c.) & BARD1 PV (p.) & Additional PVs \\
\hline 1 & HBC & Breast $(40,58)$ & ILC ER+ Her2-; TNBC & Cousin: PC (73) & \multirow{2}{*}{ c.157del } & \multirow{2}{*}{ p.(Cys53Valfs*5) } & \\
\hline 2 & HBOC & Breast (30) & IDC ER+ Her2- & & & & \\
\hline 3 & $\mathrm{HOC}$ & Ovary (59) & HGOSC & & c.176_177del & p.(Glu59Alafs*8) & \\
\hline $4^{+}$ & HBC & Breast $(27,42)$ & $\mathrm{ER}+\mathrm{BC} ; \mathrm{TNBC}$ & Mother: Breast $(44,44)$ & c.580_581del & p.(Arg194Glyfs*2) & \\
\hline
\end{tabular}


Table 2. Cont

\begin{tabular}{|c|c|c|c|c|c|c|c|}
\hline Family & Clinical Indication & Cancer Type (Age at dx) & Tumor Phenotype & Family History (Age at $\mathrm{dx}$ ) & BARD1 PV (c.) & BARD1 PV (p.) & Additional PVs \\
\hline 5 & $\mathrm{HBC}$ & Breast (38) & IDC ER+ Her2- & $\begin{array}{c}\text { Aunt: Breast (37) }{ }^{\ddagger} \text {, Aunt: } \\
\text { Breast (36) }\end{array}$ & c. $1061 \mathrm{C}>\mathrm{A}$ & p.(Ser354*) & \\
\hline 6 & $\mathrm{HOC}$ & Ovary (62) & EC & & c. $1314+1 G>A$ & p.? & \\
\hline 7 & $\mathrm{HBC}$ & Breast (49) & TNBC & & c.1349dup & p.(Asn450Lysfs*4) & \\
\hline 8 & $\mathrm{HBC}$ & Breast (31) & TNBC & $\begin{array}{c}\text { Aunt: Breast (64) } \ddagger \text {, Aunt: } \\
\text { Breast (64) } \ddagger\end{array}$ & c. $1652 C>G$ & p.(Ser551*) & \\
\hline 9 & $\mathrm{HBC}$ & Breast (56) & TNBC & & \multirow{7}{*}{ c. $1921 \mathrm{C}>\mathrm{T}$} & \multirow{7}{*}{ p.(Arg641*) } & \multirow{7}{*}{$\begin{array}{l}\text { BRCA2 c.3264dupT } \\
\text { p.(Gln1089Serfs*10) }\end{array}$} \\
\hline 10 & HBOC & Breast (54) & IDC ER+ Her2- & Mother: Ovary (63) & & & \\
\hline 11 & $\mathrm{HBC}$ & Breast (63) & TNBC & $\begin{array}{c}\text { Aunt: Breast }(60) \ddagger \text {, Cousin: } \\
\text { Breast }(54) \ddagger\end{array}$ & & & \\
\hline 12 & HBC & Breast (40) & IDC ER+ Her2+ & Mother: EC (62), Breast (64) & & & \\
\hline $\begin{array}{l}13 \\
14\end{array}$ & $\begin{array}{l}\text { HBC } \\
\text { HBC }\end{array}$ & $\begin{array}{l}\text { Breast (49) } \\
\text { Breast }(30)\end{array}$ & $\begin{array}{l}\text { TNBC } \\
\text { TNBC }\end{array}$ & & & & \\
\hline $\begin{array}{l}14 \\
15\end{array}$ & HBC & Breast $(46,56,56)$ & IDBC; bilateral IDBC & Mother: Breast (78) & & & \\
\hline $16^{\wedge}$ & $\mathrm{HBC}$ & Breast $(40,47)$ & TNBC; TNBC & $\begin{array}{c}\text { Sister: Breast (46); Sister: } \\
\text { Breast (48); Mother: Breast } \\
\text { (48); Cousin: Breast (46) }\end{array}$ & & & \\
\hline 17 & HBOC & Breast (42) & IDC ER+ Her2- & $\begin{array}{l}\text { Uncle: Breast (71); Aunt: } \\
\text { Ovary (62) }\end{array}$ & c.2129_2132del & p.(Asp710Valfs*3) & \\
\hline 18 & HOC & Ovary (62) & HGOSC & & $\begin{array}{l}\text { c. }\left(1568+1 \_1569-\right. \\
\text { 1)_(1810+1_1811-1)del } \\
\text { Exons } 7-8 \text { deletion }\end{array}$ & & \\
\hline 19 & $\mathrm{HBC}$ & Breast (44) & TNBC & $\begin{array}{c}\text { Mother: Breast (69); Aunt: } \\
\text { Breast (60) }\end{array}$ & $\begin{array}{l}\text { g.(?_215617227)_(215593730_? } \\
\text { Exons 7-11 deletion }\end{array}$ & & \\
\hline
\end{tabular}

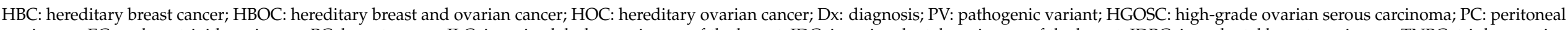

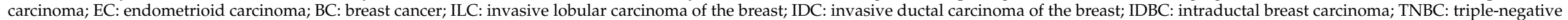

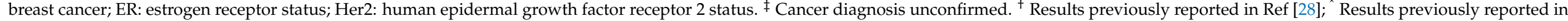
Ref [29]. 
Two recurrent variants were identified in our set of samples. BARD1 c.1921C > T; p.(Arg641*) was found in eight unrelated patients, thus representing the most frequent variant in our cohort. Besides, two unrelated patients harbored the BARD1 c.157del; p.(Cys53Valfs*5) variant. The nine remaining variants were identified in one index case each (Figure 1). It is worth mentioning that we performed RT-PCR analysis of the splicing variant c.1314+1G > A, which causes skipping of exons 3 and 4 (r.216_1314del; p.(Ser72Argfs*37)) (data not shown). Interestingly, we identified two copy number variants (CNVs) (Table 2). One consisted in the deletion of exons 7 and 8, which was experimentally validated by RT-PCR analysis in the proband's cDNA (data not shown). This variant causes an out-offrame deletion predicted to generate a truncated protein. The other CNV involved the loss of exons 7 to 11 and was validated using an MLPA custom probe. This deletion would presumably result in a BARD1 protein lacking both BRCT domains and the C-terminal region of the Ank domain. The screening of CNVs in the Genome Aggregation Database (gnomAD) splicing variants (SVs) dataset did not identify any $\mathrm{CNV}$ in the control population.

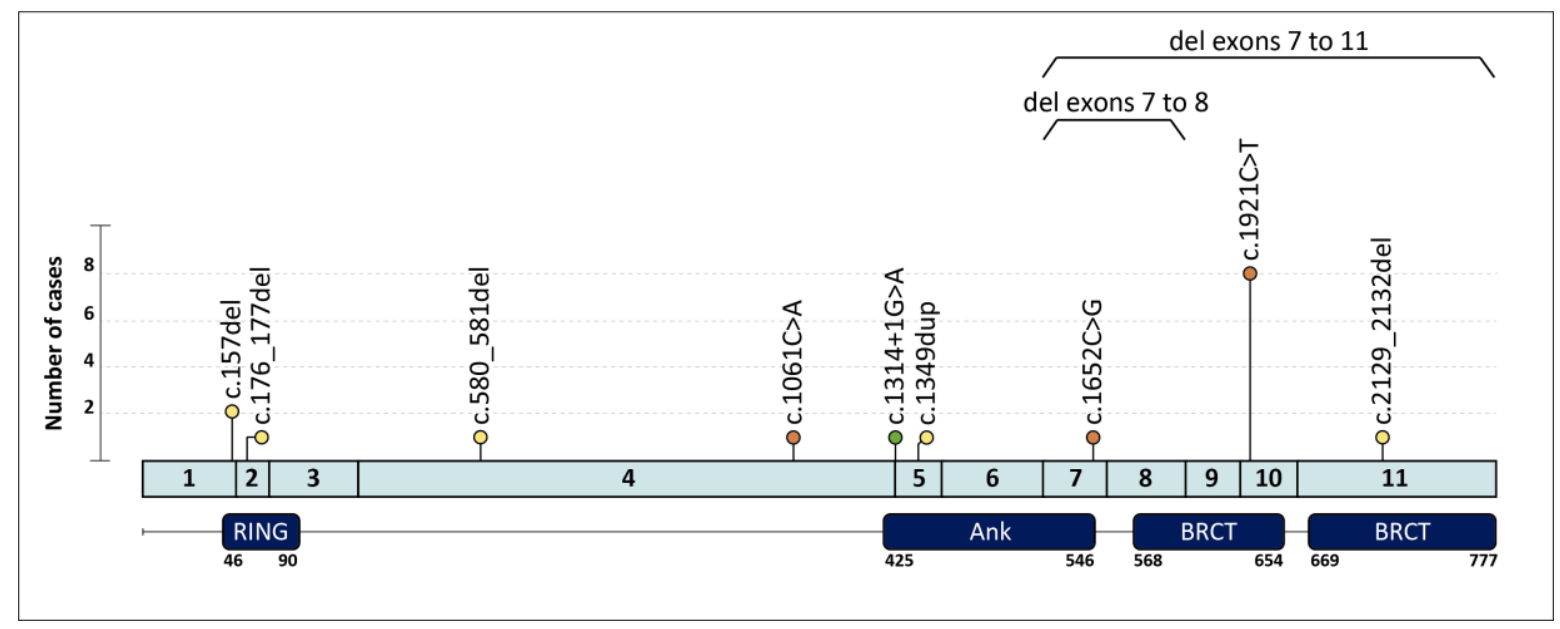

Figure 1. Spectrum of BARD1 germline pathogenic variants found in our cohort. Locations of variants are displayed by lollipop structures with the following color code: orange for nonsense variants, yellow for frameshift variants and green for splicing variants. Horizontal lines correspond to copy number variants, each found in one index case. The different BARD1 protein domains are shown in dark blue boxes with an amino acid numbered scale.

Table 3. Summary of the triple-negative status of the hereditary breast cancer cohort.

\begin{tabular}{ccc}
\hline Group & Number of Patients & BARD1-Mutated \\
\hline TNBC patients & 680 & $10(0.88 \%)$ \\
Non-TNBC patients & 2179 & OR $=5.40(1.77-18.15)$ \\
& & $0.001 * *$ \\
Total & 2859 & $16.28 \%)$ \\
\hline
\end{tabular}

TNBC: triple-negative breast cancer; OR: odds ratio. ${ }^{* *} \alpha<0.01$.

Regarding co-segregation and $\mathrm{LOH}$ studies, in a previous publication by our group, we reported the results of the co-segregation of family 16 [29]: the proband's mother, diagnosed with $\mathrm{BC}$, as well as the sister and the maternal cousin, both affected by $\mathrm{BC}$, had the same BARD1 variant; the variant was also found in the proband's 39-year-old daughter, although she was asymptomatic. In the rest of the families, the co-segregation study was scarcely informative. In family 1 , the proband's cousin was diagnosed with peritoneal carcinoma (PC) at age 73 and harbored the same BARD1 PV. In families 4 and 15, the probands inherited the $B A R D 1$ PV from their respective mothers, also affected by $B C$. However, in families 13 and 14, the probands inherited the BARD1 PV from asymptomatic mothers. $\mathrm{LOH}$ analysis could only be performed in a tumor sample from the proband in family 14, but there was no evidence of $\mathrm{LOH}$. 


\section{Discussion}

In the present study, we performed a comprehensive analysis of the BARD1 gene in a cohort of 4015 hereditary BC/OC patients. The screening for germline PVs evidenced that $B A R D 1$ heterozygous carriers have an overall increased risk $(\mathrm{OR}=3.78 ; \mathrm{CI}=2.10-6.48$; $\left.p=1.16 \times 10^{-5}\right)$. When stratified by clinical suspicion, the estimated risk for HBC patients resulted in a significant $\mathrm{OR}=4.18\left(\mathrm{CI}=2.1-7.7 ; p=5.45 \times 10^{-5}\right)$. These results are comparable to those previously reported by several case-control studies. The largest analysis to date was performed by Couch et al. in a cohort of 28,536 BC patients, proposing BARD1 as a moderate-risk gene with an $\mathrm{OR}=2.16\left(\mathrm{CI}=1.31-3.63 ; p=2.26 \times 10^{-3}\right)$ [9]. Similarly, Slavin et al. reported an $\mathrm{OR}=3.18(\mathrm{CI}=1.34-7.36 ; p=0.012)$ [10] and Weber-Lassalle et al. reported an OR $=5.35(\mathrm{CI}=3.17-9.04 ; p<0.00001)$ [11] in 2134 and 4469 familial BC patients, respectively. Besides, a recent meta-analysis by Suszynska and Kozlowski collected data from a total of 123 published studies and consistently reported an $\mathrm{OR}=2.90(\mathrm{CI}=2.25-3.75$; $p<0.0001$ ) over a cumulative cohort of $\sim 48,700 \mathrm{BC}$ patients [30]. However, there are some studies that failed to identify a significant association with $\mathrm{BC}$ risk, such as those published by Castéra et al. and Lu et al. $[15,16]$.

An increase in the prevalence of PVs in BARD1 among TNBC patients has been repeatedly suggested $[12,13,31,32]$. In agreement with this hypothesis, we identified ten $B A R D 1$ $\mathrm{PV}$ carriers from $680 \mathrm{TNBC}$ cases (carrier frequency $=0.9 \%$ ), resulting in an $\mathrm{OR}=5.40$ $(\mathrm{CI}=1.77-18.15 ; p=0.001)$. Our results are comparable to the analysis of $4090 \mathrm{TNBC}$ cases performed by Shimelis et al., who identified 25 individuals harboring BARD1 PVs $(0.61 \%)$ and obtained an $\mathrm{OR}=5.92\left(\mathrm{CI}=3.36-10.27 ; p=2.20 \times 10^{-9}\right)[14]$, whereas a surprisingly high $\mathrm{OR}=11.27(\mathrm{CI}=3.37-25.01)$ was reported by Castéra et al. [15]. Despite the reduced sample size of our subset of TNBC patients, our results support that deleterious BARD1 variants were enriched in TNBC cases. Further studies in larger cohorts will be necessary to more precisely assess the BARD1-associated risk with this tumor phenotype.

Our results also showed a trend, although non-significant, for HOC patients $(\mathrm{OR}=3.53)$. Previous studies focusing on BARD1 as an OC-predisposing gene have shown inconsistent results. Only Norquist et al. revealed a significant $\mathrm{OR}=4.2(\mathrm{CI}=1.4-12.5 ; p=0.02)$ in 1915 OC cases [18], similar to that reported in our set of samples. Contrarily, the analysis of 3261 epithelial OC cases by Ramus et al. and 6294 OC cases by Lilyquist et al. resulted in non-significant associations of deleterious $B A R D 1$ variants with OC risk $[17,19]$. The meta-analysis by Suszynska and Kozlowski could not detect an association of BARD1 with OC risk in a cumulative set of $\sim 20,800$ OC cases either [30].

Unraveling the contribution of moderate-penetrance genes to HC predisposition is challenging, as the low incidence of PVs detected in these genes results in inaccurate estimates of their associated risks. Due to the limited number of carriers identified, increasing the study size is mandatory to improve the statistical power. Besides, case-control studies usually rely on controls from publicly available databases to reach statistical power instead of using geographically matched controls (GMCs), potentially causing an overestimation of the calculated ORs [9]. Multi-centric international studies could potentially reduce this heterogeneity by defining common inclusion criteria for patients and harmonizing the methodological features. It is also very likely that the true prevalence of BARD1 PVs has been underrated. As a consequence of the lack of functional assays, we have not contemplated missense, synonymous and intronic variants in the risk calculations, as we cannot be certain of their pathogenicity.

It is worth emphasizing that we have performed a screening of CNVs in our cohort of HC patients, resulting in the identification of two large deletions (exons 7 to 8 and exons 7 to 11), accounting for $10.5 \%$ of the PVs. To our knowledge, only a small fraction of published studies have also performed this analysis and only seven CNVs have been identified so far: exon 1 deletion [33], exon 2 deletion [34], exon 1 to 6 deletion [35], exon 5 to 7 deletion [36], exon 8 to 11 deletion [37] and two whole-gene deletions [37,38]. While no CNVs were identified in the gnomAD SV control population dataset, analysis of BARD1 
CNVs in HC cohorts is strongly recommended considering the significant contribution in our series of this kind of variant.

$B A R D 1$ has been included in multi-gene panels since it was regarded as a potential cancer-predisposing gene [39], despite the lack of robust risk estimates. The identification of BARD1 PV carriers should be taken with caution, as inherited PVs in moderate- to low-penetrance genes may not necessarily be responsible for all the cancer diagnoses in a family. Nevertheless, although the clinical evidence available to date is still insufficient to impact risk management, continued testing of $B A R D 1$ will permit access to the carrier status once recommendations for $B A R D 1 \mathrm{PV}$ carriers become available in the future.

Taken together, our results confirm $B A R D 1$ as a $B C$ susceptibility gene and highlight a stronger association with triple-negative tumors. Future studies aimed at screening larger cohorts and refining the classification of $B A R D 1$ variants will help to elucidate its role as a breast and/or ovarian cancer gene as well as define medical recommendations for BARD1 PV carriers.

Author Contributions: BARD1 data analysis: P.R., J.D.V., S.T.-E., L.F., J.M.M.-C., A.L.-D., R.D.C., G.C., J.B. (Joan Brunet) and J.B. (Judith Balmaña); Genetic tests: P.R., O.C., R.C. and O.D.; Collection and analysis of clinical information: P.R., J.D.V., S.T.-E., L.F., A.S., E.M., Á.T., È.G. and J.S.; Integration and comprehensive analysis of data: P.R., J.D.V. and C.L.; Writing: P.R., J.D.V. and C.L.; All authors have read and agreed to the published version of the manuscript.

Funding: Contract grant sponsor: Supported by the Carlos III National Health Institute funded by FEDER funds—a way to build Europe-(PI19/00553; PI16/00563; PI16/01898; PI16/11363; PI15/00355; PI12/02585; SAF2015-68016-R and CIBERONC); the Government of Catalonia (Pla estratègic de recerca i innovació en salut (PERIS_MedPerCan and URDCat projects), 2017SGR1282 and 2017SGR496); and CERCA Programa/Generalitat de Catalunya for institutional support. GCAT is supported by Acción de Dinamización del ISCIII-MINECO (ADE 10/00026), by the Ministry of Health of the Generalitat of Catalunya and by Agència de Gestió d'Ajuts Universitaris i de Recerca (AGAUR) (2017-SGR 529) and GCAT Cession Research Project PI-2018-09 GCAT_CM.

Institutional Review Board Statement: The study was conducted according to the guidelines of the Declaration of Helsinki and approved by the ethics committee of Bellvitge Biomedical Research Institute (IDIBELL; PR278/19) and Vall d'Hebron Hospital (PRAG102-2016).

Informed Consent Statement: Informed consent was obtained from all subjects involved in the study.

Data Availability Statement: Data is contained within the article.

Acknowledgments: We thank the CERCA Program/Generalitat de Catalunya for their institutional support. We also wish to thank all members of the ICO Hereditary Cancer Program and the Hereditary Cancer Genetics Group at Hospital Vall d'Hebron. This study makes use of data generated by IGTP, specifically by its research group the GCAT-Genomes for Life Cohort study of the Genomes of Catalonia, IGTP. A full list of the investigators who contributed to the generation of the data is available from http:/ / www.genomesforlife.com/. IGTP is part of the CERCA Program/Generalitat de Catalunya.

Conflicts of Interest: The authors declare no conflict of interest.

\section{References}

1. De Brakeleer, S.; De Grève, J.; Loris, R.; Janin, N.; Lissens, W.; Sermijn, E.; Teugels, E. Cancer predisposing missense and protein truncating BARD1 mutations in non-BRCA1 or BRCA2 breast cancer families. Hum. Mutat. 2010, 31, e1175-e1185. [CrossRef] [PubMed]

2. Easton, D.F.; Pharoah, P.D.P.; Antoniou, A.C.; Tischkowitz, M.; Tavtigian, S.V.; Nathanson, K.L.; Devilee, P.; Meindl, A.; Couch, F.J.; Southey, M.; et al. Gene-panel sequencing and the prediction of breast-cancer risk. N. Engl. J. Med. 2015, 372, $2243-2257$. [CrossRef] [PubMed]

3. Wu, L.C.; Wang, Z.W.; Tsan, J.T.; Spillman, M.A.; Phung, A.; Xu, X.L.; Yang, M.C.W.; Hwang, L.Y.; Bowcock, A.M.; Baer, R. Identification of a RING protein that can interact in vivo with the BRCA1 gene product. Nat. Genet. 1996, 14, 430-440. [CrossRef] [PubMed]

4. Fox, D.; Le Trong, I.; Rajagopal, P.; Brzovic, P.S.; Stenkamp, R.E.; Klevit, R.E. Crystal structure of the BARD1 ankyrin repeat domain and its functional consequences. J. Biol. Chem. 2008, 283, 21179-21186. [CrossRef] 
5. Birrane, G.; Varma, A.K.; Soni, A.; Ladias, J.A.A. Crystal structure of the BARD1 BRCT domains. Biochemistry 2007, 46, 7706-7712. [CrossRef]

6. Hashizume, R.; Fukuda, M.; Maeda, I.; Nishikawa, H.; Oyake, D.; Yabuki, Y.; Ogata, H.; Ohta, T. The RING heterodimer BRCA1-BARD1 is a ubiquitin ligase inactivated by a breast cancer-derived mutation. J. Biol. Chem. 2001, 276, 14537-14540. [CrossRef]

7. Moynahan, M.E.; Chiu, J.W.; Koller, B.H.; Jasint, M. Brca1 controls homology-directed DNA repair. Mol. Cell 1999, 4, 511-518. [CrossRef]

8. Feki, A.; Jefford, C.E.; Berardi, P.; Wu, J.Y.; Cartier, L.; Krause, K.H.; Irminger-Finger, I. BARD1 induces apoptosis by catalysing phosphorylation of p53 by DNA-damage response kinase. Oncogene 2005, 24, 3726-3736. [CrossRef]

9. Couch, F.J.; Shimelis, H.; Hu, C.; Hart, S.N.; Polley, E.C.; Na, J.; Hallberg, E.; Moore, R.; Thomas, A.; Lilyquist, J.; et al. Associations between cancer predisposition testing panel genes and breast cancer. JAMA Oncol. 2017, 3, 1190-1196. [CrossRef]

10. Slavin, T.P.; Maxwell, K.N.; Lilyquist, J.; Vijai, J.; Neuhausen, S.L.; Hart, S.N.; Ravichandran, V.; Thomas, T.; Maria, A.; Villano, D.; et al. The contribution of pathogenic variants in breast cancer susceptibility genes to familial breast cancer risk. npj Breast Cancer 2017, 3, 1-10. [CrossRef]

11. Weber-Lassalle, N.; Borde, J.; Weber-Lassalle, K.; Horváth, J.; Niederacher, D.; Arnold, N.; Kaulfuß, S.; Ernst, C.; Paul, V.G.; Honisch, E.; et al. Germline loss-of-function variants in the BARD1 gene are associated with early-onset familial breast cancer but not ovarian cancer. Breast Cancer Res. 2019, 21, 55. [CrossRef] [PubMed]

12. De Brakeleer, S.; De Grève, J.; Desmedt, C.; Joris, S.; Sotiriou, C.; Piccart, M.; Pauwels, I.; Teugels, E. Frequent incidence of BARD1-truncating mutations in germline DNA from triple-negative breast cancer patients. Clin. Genet. 2016, 89, 336-340. [CrossRef] [PubMed]

13. González-Rivera, M.; Lobo, M.; López-Tarruella, S.; Jerez, Y.; del Monte-Millán, M.; Massarrah, T.; Ramos-Medina, R.; Ocaña, I.; Picornell, A.; Garzón, S.S.; et al. Frequency of germline DNA genetic findings in an unselected prospective cohort of triplenegative breast cancer patients participating in a platinum-based neoadjuvant chemotherapy trial. Breast Cancer Res. Treat. 2016, 156, 507-515. [CrossRef] [PubMed]

14. Shimelis, H.; LaDuca, H.; Hu, C.; Hart, S.N.; Na, J.; Thomas, A.; Akinhanmi, M.; Moore, R.M.; Brauch, H.; Cox, A.; et al. Triple-negative breast cancer risk genes identified by multigene hereditary cancer panel testing. J. Natl. Cancer Inst. 2018, 110, 855-862. [CrossRef] [PubMed]

15. Castéra, L.; Harter, V.; Muller, E.; Krieger, S.; Goardon, N.; Ricou, A.; Rousselin, A.; Paimparay, G.; Legros, A.; Bruet, O.; et al. Landscape of pathogenic variations in a panel of 34 genes and cancer risk estimation from $5131 \mathrm{HBOC}$ families. Genet. Med. 2018, 20, 1677-1686. [CrossRef] [PubMed]

16. Lu, H.M.; Li, S.; Black, M.H.; Lee, S.; Hoiness, R.; Wu, S.; Mu, W.; Huether, R.; Chen, J.; Sridhar, S.; et al. Association of Breast and Ovarian Cancers with Predisposition Genes Identified by Large-Scale Sequencing. JAMA Oncol. 2019, 5, 51-57. [CrossRef]

17. Ramus, S.J.; Song, H.; Dicks, E.; Tyrer, J.P.; Rosenthal, A.N.; Intermaggio, M.P.; Fraser, L.; Gentry-Maharaj, A.; Hayward, J.; Philpott, S.; et al. Germline mutations in the BRIP1, BARD1, PALB2, and NBN genes in women with ovarian cancer. J. Natl. Cancer Inst. 2015, 107. [CrossRef]

18. Norquist, B.M.; Harrell, M.I.; Brady, M.F.; Walsh, T.; Lee, M.K.; Gulsuner, S.; Bernards, S.S.; Casadei, S.; Yi, Q.; Burger, R.A.; et al. Inherited mutations in women with ovarian carcinoma. JAMA Oncol. 2016, 2, 482-490. [CrossRef]

19. Lilyquist, J.; LaDuca, H.; Polley, E.; Davis, B.T.; Shimelis, H.; Hu, C.; Hart, S.N.; Dolinsky, J.S.; Couch, F.J.; Goldgar, D.E. Frequency of mutations in a large series of clinically ascertained ovarian cancer cases tested on multi-gene panels compared to reference controls. Gynecol. Oncol. 2017, 147, 375-380. [CrossRef]

20. Obón-Santacana, M.; Vilardell, M.; Carreras, A.; Duran, X.; Velasco, J.; Galván-Femenía, I.; Alonso, T.; Puig, L.; Sumoy, L.; Duell, E.J.; et al. GCAT I Genomes for life: A prospective cohort study of the genomes of Catalonia. BMJ Open 2018, 8, 18324. [CrossRef]

21. Castellanos, E.; Gel, B.; Rosas, I.; Tornero, E.; Santín, S.; Pluvinet, R.; Velasco, J.; Sumoy, L.; Del Valle, J.; Perucho, M.; et al. A comprehensive custom panel design for routine hereditary cancer testing: Preserving control, improving diagnostics and revealing a complex variation landscape. Sci. Rep. 2017, 7. [CrossRef]

22. Fowler, A.; Mahamdallie, S.; Ruark, E.; Seal, S.; Ramsay, E.; Clarke, M.; Uddin, I.; Wylie, H.; Strydom, A.; Lunter, G.; et al. Accurate clinical detection of exon copy number variants in a targeted NGS panel using DECoN. Wellcome Open Res. $2016,1,20$. [CrossRef] [PubMed]

23. Moreno-Cabrera, J.M.; del Valle, J.; Castellanos, E.; Feliubadaló, L.; Pineda, M.; Brunet, J.; Serra, E.; Capellà, G.; Lázaro, C.; Gel, B. Evaluation of CNV detection tools for NGS panel data in genetic diagnostics. Eur. J. Hum. Genet. 2020, 28. [CrossRef]

24. Feliubadaló, L.; López-Fernández, A.; Pineda, M.; Díez, O.; del Valle, J.; Gutiérrez-Enríquez, S.; Teulé, A.; González, S.; Stjepanovic, N.; Salinas, M.; et al. Opportunistic testing of BRCA1, BRCA2 and mismatch repair genes improves the yield of phenotype driven hereditary cancer gene panels. Int. J. Cancer 2019, 145, 2682-2691. [CrossRef]

25. Richards, S.; Aziz, N.; Bale, S.; Bick, D.; Das, S.; Gastier-Foster, J.; Grody, W.W.; Hegde, M.; Lyon, E.; Spector, E.; et al. Standards and guidelines for the interpretation of sequence variants: A joint consensus recommendation of the American College of Medical Genetics and Genomics and the Association for Molecular Pathology. Genet. Med. 2015, 17, 405-424. [CrossRef] [PubMed] 
26. den Dunnen, J.T.; Dalgleish, R.; Maglott, D.R.; Hart, R.K.; Greenblatt, M.S.; Mcgowan-Jordan, J.; Roux, A.F.; Smith, T.; Antonarakis, S.E.; Taschner, P.E.M. HGVS recommendations for the description of sequence variants: 2016 update. Hum. Mutat. 2016, 37, 564-569. [CrossRef] [PubMed]

27. Karczewski, K.J.; Francioli, L.C.; Tiao, G.; Cummings, B.B.; Alföldi, J.; Wang, Q.; Collins, R.L.; Laricchia, K.M.; Ganna, A.; Birnbaum, D.P.; et al. The mutational constraint spectrum quantified from variation in 141,456 humans. Nature $2020,581$. [CrossRef] [PubMed]

28. Bonache, S.; Esteban, I.; Moles-Fernández, A.; Tenés, A.; Duran-Lozano, L.; Montalban, G.; Bach, V.; Carrasco, E.; Gadea, N.; López-Fernández, A.; et al. Multigene panel testing beyond BRCA1/2 in breast/ovarian cancer Spanish families and clinical actionability of findings. J. Cancer Res. Clin. Oncol. 2018, 144, 2495-2513. [CrossRef]

29. Feliubadaló, L.; Tonda, R.; Gausachs, M.; Trotta, J.R.; Castellanos, E.; López-Doriga, A.; Teulé, À.; Tornero, E.; Del Valle, J.; Gel, B.; et al. Benchmarking of whole exome sequencing and Ad Hoc designed panels for genetic testing of hereditary cancer. Sci. Rep. 2017, 7, 1-11. [CrossRef] [PubMed]

30. Suszynska, M.; Kozlowski, P. Summary of bard1 mutations and precise estimation of breast and ovarian cancer risks associated with the mutations. Genes (Basel) 2020, 11, 798. [CrossRef]

31. Couch, F.J.; Hart, S.N.; Sharma, P.; Toland, A.E.; Wang, X.; Miron, P.; Olson, J.E.; Godwin, A.K.; Pankratz, V.S.; Olswold, C.; et al. Inherited mutations in 17 breast cancer susceptibility genes among a large triple-negative breast cancer cohort unselected for family history of breast cancer. J. Clin. Oncol. 2015, 33, 304-311. [CrossRef] [PubMed]

32. Buys, S.S.; Sandbach, J.F.; Gammon, A.; Patel, G.; Kidd, J.; Brown, K.L.; Sharma, L.; Saam, J.; Lancaster, J.; Daly, M.B. A study of over 35,000 women with breast cancer tested with a 25-gene panel of hereditary cancer genes. Cancer 2017, 123, 1721-1730. [CrossRef] [PubMed]

33. Tung, N.; Battelli, C.; Allen, B.; Kaldate, R.; Bhatnagar, S.; Bowles, K.; Timms, K.; Garber, J.E.; Herold, C.; Ellisen, L.; et al. Frequency of mutations in individuals with breast cancer referred for BRCA1 and BRCA2 testing using next-generation sequencing with a 25-gene panel. Cancer 2015, 121, 25-33. [CrossRef] [PubMed]

34. Adedokun, B.; Zheng, Y.; Ndom, P.; Gakwaya, A.; Makumbi, T.; Zhou, A.Y.; Yoshimatsu, T.F.; Rodriguez, A.; Madduri, R.K.; Foster, I.T.; et al. Prevalence of inherited mutations in breast cancer predisposition genes among women in Uganda and Cameroon. Cancer Epidemiol. Biomarkers Prev. 2020, 29, 359-367. [CrossRef]

35. Zeng, C.; Guo, X.; Wen, W.; Shi, J.; Long, J.; Cai, Q.; Shu, X.O.; Xiang, Y.; Zheng, W. Evaluation of pathogenetic mutations in breast cancer predisposition genes in population-based studies conducted among Chinese women. Breast Cancer Res. Treat. 2020, 181, 465-473. [CrossRef]

36. Kaneyasu, T.; Mori, S.; Yamauchi, H.; Ohsumi, S.; Ohno, S.; Aoki, D.; Baba, S.; Kawano, J.; Miki, Y.; Matsumoto, N.; et al. Prevalence of disease-causing genes in Japanese patients with BRCA1/2-wildtype hereditary breast and ovarian cancer syndrome. npj Breast Cancer 2020, 6. [CrossRef]

37. Carter, N.J.; Marshall, M.L.; Susswein, L.R.; Zorn, K.K.; Hiraki, S.; Arvai, K.J.; Torene, R.I.; McGill, A.K.; Yackowski, L.; Murphy, P.D.; et al. Germline pathogenic variants identified in women with ovarian tumors. Gynecol. Oncol. 2018, 151, 481-488. [CrossRef]

38. Kwong, A.; Shin, V.Y.; Chen, J.; Cheuk, I.W.Y.; Ho, C.Y.S.; Au, C.H.; Chan, K.K.L.; Ngan, H.Y.S.; Chan, T.L.; Ford, J.M.; et al. Germline mutation in 1338 BRCA-negative Chinese hereditary breast and/or ovarian cancer patients: Clinical testing with a multigene test panel. J. Mol. Diagn. 2020, 22, 544-554. [CrossRef]

39. Alenezi, W.M.; Fierheller, C.T.; Recio, N.; Tonin, P.N. Literature review of BARD1 as a cancer predisposing gene with a focus on breast and ovarian cancers. Genes (Basel) 2020, 11, 856. [CrossRef] 